Bidang ilmu : Ilmu Gizi

\title{
HUBUNGAN KALIUM, PERSENTASE LEMAK TUBUH, DAN KEPATUHAN DIET RENDAH GARAM
}

\author{
Amelia Eka Putri1), Sintha Fransiske Simanungkalit2) \\ Fakultas Ilmu Kesehatan \\ Universitas Pembangunan Nasional Veteran Jakarta \\ ameliaekaputri@upnvj.ac.id1)
}

\begin{abstract}
ABSTRAK
Hipertensi masih menjadi masalah kesehatan yang menyebabkan kematian diseluruh dunia. Pada tahun 2018, Indonesia memiliki prevalensi hipertensi berdasarkan umur diatas 18 tahun sebesar $34.1 \%$. Hipertensi tidak terkontrol adalah seseorang yang mengalami hipertensi dengan kondisi tekanan darah lebih besar atau sama dengan $140 \mathrm{mmHg} / 90 \mathrm{mmHg}$ dan tidak melakukan pemeriksaan secara berkala. Penelitian ini bertujuan untuk mengetahui hubungan antara asupan kalium, presentase lemak tubuh dan kepatuhan diet rendah garam dengan kejadian hipertensi terkontrol dan tidak terkontrol pada pralansia di RW 03 Lubang Buaya dan RW 09 Kampung Tengah, Jakarta Tahun 2020. Penelitian ini menggunakan desain cross sectional. Jumlah sampel sebanyak 81 responden yang diambil dengan teknik simple random sampling. Instrumen penelitian menggunakan formulir semi quantitative food frequency questionnaire, Bioelectrical impedance analysis dan kuesioner kepatuhan diet rendah garam. Hasil analisis menggunakan uji chi square didapatkan asupan kalium $(p=0.182)$, persentase lemak tubuh $(p=0.984)$, kepatuhan diet rendah garam $(p=0.000)$. Terdapat hubungan antara kepatuhan diet rendah garam dengan kejadian hipertensi terkontrol dan tidak terkontrol pada pralansia. Sedangkan, asupan kalium dan presentase lemak tubuh tidak menunjukkan adanya hubungan dengan kejadian hipertensi terkontrol dan tidak terkontrol pada pralansia. Sehingga, diharapkan kepada kader di posbindu agar aktif memberikan edukasi terkait hipertensi dan pentingnya menjaga tekanan darah agar tetap terkendali
\end{abstract}

Kata Kunci : Hipertensi; Kalium; Kepatuhan Diet; Persentase Lemak Tubuh

\begin{abstract}
Hypertension is still a health problem that causes death worldwide. In 2018, Indonesia has a prevalence of hypertension based on age over 18 years of $34.1 \%$. Uncontrolled hypertension is someone who has hypertension with a condition of blood pressure greater than or equal to $140 \mathrm{mmHg} / 90 \mathrm{mmHg}$ and does not do regular checks. This study aims to determine the relationship between potassium intake, body fat percentage and low salt diet adherence with the incidence of controlled and uncontrolled hypertension in pre-elderly at RW 03 Lubang Buaya and RW 09 Kampung Tengah, Jakarta 2020. This study used a cross sectional design. The total sample of 81 respondents taken by simple random sampling technique. The research instrument used a semi quantitative food frequency questionnaire form, Bioelectrical impedance analysis and a low salt diet compliance questionnaire. The results of the analysis using the chi square test obtained potassium intake $(p=0.182)$, body fat percentage $(p=0.984)$, low salt diet compliance $(p=0.000)$. There is a relationship between low-salt diet adherence with the incidence of controlled and uncontrolled hypertension in pre elderly. Meanwhile, potassium intake and body fat percentage did not show any relationship with the incidence of controlled and uncontrolled hypertension in pre-elderly. Thus, it is hoped that cadres in Posbindu will be active in providing education related to hypertension and the importance of maintaining blood pressure in order to remain under control.
\end{abstract}

Keywords: Body Fat Percentage; Diet Adherence; Hypertension; Potassium

Alamat Korespondensi : Fakultas Ilmu Kesehatan, UPN Veteran Jakarta, Jalan Limo Raya, Cinere Depok Email : ameliaekaputri@upnvj.ac.id. Nomor Hp : 085889164443 


\section{PENDAHULUAN}

Pralansia termasuk kedalam kategori kelompok yang mengalami proses penuaan dan akibat dari proses penuaan bisa meningkatkan kejadian penyakit tidak menular (PTM) (Liman, Arif, \& Surjadi, 2015). Satu dari empat jenis penyakit tidak menular merupakan penyakit pada sistem kardiovaskuler. Hipertensi merupakan tekanan darah yang mengalami suatu peningkatan diatas normal dalam pembuluh darah arteri yang akan mengangkut darah dari jantung dan kemudian dipompa keseluruh tubuh secara terus-menerus (Desriyani, Wahyudi, \& Suratun, 2019). Organisasi Kesehatan Dunia menyatakan bahwa di dunia prevalensi peningkatan tekanan darah tertinggi terdapat di wilayah Afrika (46\%), dan untuk wilayah Asia Tenggara kejadian hipertensi pada orang dewasa lebih dari 25 tahun mencapai 36\% (World Health Organization, 2013). Berdasarkan Riset Kesehatan Dasar terbaru prevalensi hipertensi mengalami peningkatan kembali menjadi 34,1\% dan untuk kategori hipertensi menurut kelompok usia 44 - 54 tahun mencapai (45,32\%) (Litbangkes RI, 2018). Dinas kesehatan kota DKI Jakarta menyatakan angka kejadian hipertensi pada wilayah Jakarta timur yaitu 19.09\% (Dinkes DKI Jakarta, 2018). Berdasarkan data studi pendahuluan terhadap 10 orang pralansia di lingkungan RW 03 Lubang buaya didapatkan 7 orang termasuk kedalam hipertensi tidak terkontrol dan 3 orang mempunyai hipertensi yang terkontrol. Sedangkan, di lingkungan RW 09 Kampung Tengah didapatkan 6 orang mempunyai hipertensi tidak terkontrol dan hipertensi terkontrol sebanyak 4 orang. Beberapa penelitian mengatakan klasifikasi hipertensi terdiri dari hipertensi terkontrol dan tidak terkontrol. Hipertensi yang tidak terkontrol akan menyebabkan peluang 7 kali lebih besar terkena stroke, 6 kali terkena congestive heart failure dan 3 kali lebih besar terkena serangan jantung.

Salah satu cara mencegah agar hipertensi tidak mengalami komplikasi dengan mengendalikan faktor risikonya. Faktor risiko hipertensi dapat dibagi menjadi dua, faktor yang tidak dapat diubah (seperti usia, jenis kelamin, genetik) dan dapat diubah (seperti kurangnya aktifitas fisik, berat badan lebih, merokok, konsumsi alkohol dan natrium) (Anwar, 2014).World Health Organization menyarankan untuk mengonsumsi makanan yang sehat terdiri dari buah - buahan dan sayuran karena menyediakan zat gizi seperti kalium dan serat sehingga dapat mengontrol tekanan darah. Kalium merupakan salah satu elektrolit yang berperan penting dalam tubuh dan idealnya asupan kalium adalah $4.7 \mathrm{~g} /$ hari (Putri \& Kartini, 2014). Hasil penelitian (Kusumastuty, 2016) menyatakan bahwa asupan kalium yang tinggi akan menyebabkan tekanan darah sistolik dan diastolik pada pasien hipertensi mengalami penurunan. Indikator obesitas yang sering dikaitkan dengan peningkatan tekanan darah diantaranya lingkar pinggang dan presentase lemak tubuh. Berdasarkan data Scottish Health Surveys (2003,2008-2011) and Health Surveys for England (2003-2006, 2008- 2013) ditemukan bahwa pasien dengan hipertensi terkontrol (24.8\%) dan tidak terkontrol (41.4\%) memiliki persentase lemak tubuh lebih tinggi dibandingkan dengan individu normotensif (11.8\%) (Ma et al., 2019). Kepatuhan diet rendah garam berpengaruh terhadap kestabilan tekanan darah pada pasien hipertensi. Sebuah penelitian yang dilakukan oleh (Yuliana, Aniestia, Handayani, \& Fitria, 2014) terhadap penderita hipertensi didapatkan hasil bahwa sebanyak $65 \%$ responden tidak patuh dalam pelaksanaan diet rendah garam dan sebanyak $35 \%$ patuh dalam pelaksanaan diet rendah garam. Selain itu, rerata asupan natrium pada pasien hipertensi yang tidak terkontrol didapatkan asupan natrium sebanyak $3599 \pm 258 \mathrm{mg} /$ hari, secara signifikan lebih besar dari kelompok hipertensi yang terkontrol yaitu $2654 \pm 540 \mathrm{mg} /$ hari (Kamran, Azadbakht, Sharifirad, Mahaki, \& Sharghi, 2014). Sehingga, kesadaran pada penderita hipertensi untuk patuh menjalankan diet rendah garam sangat penting untuk dilakukan dengan atau tanpa adanya rasa sakit akibat hipertensi (Purwandari, 2017).

Dari uraian latar belakang diatas, peneliti tertarik untuk melakukan penelitian mengenai hubungan antara asupan kalium, presentase lemak tubuh dan kepatuhan diet rendah garam dengan kejadian hipertensi terkontrol dan tidak terkontrol pada pralansia di RW 03 Lubang Buaya dan RW 09 Kampung Tengah, Jakarta Tahun 2020.

\section{METODE PENELITIAN}

Penelitian ini dilakukan pada bulan April- Mei tahun 2020 dan bertempat di wilayah RW 03 Lubang Buaya dan RW 09 Kampung Tengah, Jakarta. Desain penelitian ini menggunakan cross sectional. Populasi dalam penelitian adalah Seluruh warga yang menderita hipertensi di lingkungan 
RW 03 Lubang buaya sebanyak 98 orang dan di lingkungan RW 09 Kampung Tengah berjumlah 77 orang. Sehingga jumlah populasi penderita hipertensi dari dua RW sebanyak 175 orang. Jumlah sampel yang diambil adalah 81 oramg. Teknik pengambilan sampel dengan cara Simple Random sampling berdasarkan kriteria inklusi dan eksklusi. Data primer diperoleh langsung dengan melakukan pengukuran tekanan darah penderita hipertensi yang dibantu oleh perawat, data asupan kalium didapat dari hasil wawancara menggunakan formulir semi quantitative food frequency, pengukuran lemak tubuh menggunakan alat BIA (Bioelectrical Impedance Analysis), dan kuesioner kepatuhan diet rendah garam. Data sekunder dalam penelitian ini diperoleh dari data posbindu RW 03 Lubang Buaya dan RW 09 Kampung Tengah berat badan, tinggi badan dan usia responden.

Data yang diperoleh dari hasil wawancara dengan menggunakan kuesioner dan lembar SQ-FFQ akan diolah dengan komputerisasi dan mengikuti 4 langkah yaitu editing, coding, entry data dan pembersihan data. Data tekanan darah setelah diperiksa dengan sphygnomanometer kemudian hasil pemeriksaan dikategorikan menjadi dua yaitu (Hipertensi tidak terkontrol $\geq 140 / \geq 90 \mathrm{mmHg}$ dan Hipertensi terkontrol $<140 / 90 \mathrm{mmHg}$ ). Data asupan kalium dikategorikan menjadi (kurang <3619 mg dan cukup $\geq 3619 \mathrm{mg}$ ) dan data kepatuhan diet rendah garam menjadi (tidak patuh <mean dan patuh $\geq$ mean). Pada penelitian ini akan dilakukan analisis bivariat dengan menggunakan uji chi square.

\section{HASIL DAN PEMBAHASAN}

Tabel 1. Distribusi Karakteristik Responden di RW 03 Lubang Buaya dan RW 09 Kampung Tengah, Jakarta Tahun 2020

\begin{tabular}{ccc}
\hline $\begin{array}{c}\text { Karakteristik } \\
\text { Responden }\end{array}$ & Frekuensi (n) & $\begin{array}{c}\text { Persentase } \\
\mathbf{( \% )}\end{array}$ \\
\hline $\begin{array}{c}\text { Usia } \\
45-54 \text { tahun }\end{array}$ & 51 & 63.0 \\
$55-59$ tahun & 30 & 37.0 \\
\hline Total & 81 & 100.0 \\
\hline Jenis Kelamin & & \\
Perempuan & 55 & 67.9 \\
Laki-Laki & 26 & 32.1 \\
\hline Total & 81 & 100.0 \\
\hline
\end{tabular}

Tabel 2. Analisis Hubungan Asupan Kalium, Persentase Lemak Tubuh, dan Kepatuhan Diet Rendah Garam Dengan Kejadian Hipertensi Terkontrol dan Tidak Terkontrol Pada Pralansia di RW 03 Lubang Buaya dan RW 09 Kampung Tengah, Jakarta Tahun 2020

\begin{tabular}{|c|c|c|c|c|c|c|c|c|c|}
\hline \multirow{3}{*}{ No } & \multirow{3}{*}{ Variabel } & \multirow{3}{*}{ Kategori } & \multicolumn{4}{|c|}{ Hipertensi } & \multirow{2}{*}{\multicolumn{2}{|c|}{ Jumlah }} & \multirow{2}{*}{$\begin{array}{c}\mathrm{P} \\
\text { Value }\end{array}$} \\
\hline & & & \multicolumn{2}{|c|}{$\begin{array}{c}\text { Tidak } \\
\text { Terkontrol }\end{array}$} & \multicolumn{2}{|c|}{ Terkontrol } & & & \\
\hline & & & $\mathbf{n}$ & $\%$ & $\mathbf{N}$ & $\%$ & $\mathbf{N}$ & $\%$ & \multirow[t]{3}{*}{0.182} \\
\hline \multirow[t]{2}{*}{1.} & \multirow[t]{2}{*}{ Asupan Kalium } & Kurang & 25 & 54.3 & 21 & 45.7 & 46 & 100.0 & \\
\hline & & Cukup & 25 & 71.4 & 10 & 28.6 & 35 & 100.0 & \\
\hline \multirow[t]{2}{*}{2.} & \multirow[t]{2}{*}{ Persentase Lemak Tubuh } & Obesitas & 26 & 60.5 & 17 & 39.5 & 43 & 100.0 & \multirow[t]{2}{*}{0.984} \\
\hline & & $\begin{array}{c}\text { Tidak } \\
\text { Obesitas }\end{array}$ & 24 & 63.2 & 14 & 36.8 & 38 & 100.0 & \\
\hline 3. & $\begin{array}{c}\text { Kepatuhan Diet Rendah } \\
\text { Garam }\end{array}$ & $\begin{array}{l}\text { Tidak } \\
\text { Patuh }\end{array}$ & 42 & 89.4 & 5 & 10.6 & 47 & 100.0 & 0.000 \\
\hline
\end{tabular}




\section{Karakteristik Responden}

Berdasarkan distribusi karakteristik responden dalam penelitian ini. Tabel 1 memberika informasi bahwa secara umum responden dalam penelitian ini memiliki rentang usia 45-54 tahun lebih banyak yaitu 51 responden $(63.0 \%)$ dibandingkan dengan responden yang memiliki rentang usia 55-59 tahun yaitu 30 responden (37.0\%). Sedangkan, responden lebih banyak berjenis kelamin perempuan yaitu sebanyak 55 responden (67.9\%) dibandingkan dengan responden berjenis kelamin laki-laki yaitu 26 responden $(32.1 \%)$.

\section{Hubungan Asupan Kalium dengan Kejadian Hipertensi Terkontrol dan Tidak Terkontrol pada Pralansia}

Berdasarkan hasil penelitian pada (Tabel. 2) dengan menggunakan uji chi-square didapatkan hasil bahwa tidak ada hubungan yang signifikan antara asupan kalium dengan kejadian hipertensi terkontrol dan tidak terkontrol pada pralansia dengan nilai $p$-value 0.182 ( $\mathrm{p}>0.05)$. Hasil penelitian ini sejalan dengan hasil penelitian (Kurniasih, Pangestuti, \& Aruben, 2017), (Afifah, 2016) dan (Putri \& Kartini, 2014) yang menyatakan tidak adanya hubungan antara asupan kalium dengan kejadian hipertensi.

Pada penelitian ini, tidak di temukan adanya hubungan antara asupan kalium dengan kejadian hipertensi karena penelitian ini hanya melihat asupan kalium tanpa melihat rasio natrium dan kalium. Rasio natrium dan kalium mempunyai hubungan yang lebih kuat terhadap tekanan darah dibandingkan dengan asupan kalium atau natrium itu sendiri. Rasio natrium kalium terjadi karena pada saat proses pemasakan menambahkan garam atau terjadinya peningkatan natrium dalam makanan yang menyebabkan hilangnya kalium dalam bahan makanan (Fitri, Rusmikawati, Zulfah, \& Nurbaiti, 2018). Penelitian yang telah dilakukan oleh (Saint-remy, Somja, Gellner, Weekers, \& Bonvoisin, 2012) menyatakan bahwa pasien dengan tekanan darah terkontrol dan tidak terkontrol tidak berbeda dalam mengonsumsi garam, tetapi pada pasien yang memiliki tekanan darah terkontrol ditemukan secara teratur mengonsumsi kalium dalam jumlah yang tinggi yang berasal dari buah dan sayuran. Hal ini dapat terlihat dari rasio $\mathrm{Na}+$ yang di ekskresikan tidak berbeda antara yang terkontrol dan tidak terkontrol tetapi untuk pasien dengan tekanan darah tidak terkontrol secara signifikan mengeskresikan lebih sedikit $\mathrm{K}+(\mathrm{p}=0.029)$. Asupan kalium yang tinggi juga dapat menurunkan sensitivitas garam dan mengurangi kebutuhan akan obat antihipertensi (Saint-remy et al., 2012).

Kalium yang tinggi dalam makanan akan meningkatkan konsentrasi sel ditubular ginjal yang kemudian akan merangsang pengaturan gradient konsentrasi sekresi kation pada lumen tubular ginjal sehinggan eksresi kalium meningkat. Kemudian, kalium dapat menstimulasi tubulus distal untuk reabsorpsi natrium dan meningkatkan sekresi kalium dengan cara meningkatkan hormon aldosteron sehingga terjadi perubahan level plasma kalium yang secara langsung akan merangsang aldosteron pada kelenjar korteks adrenal. Hal ini akan membuat perfusi pada ginjal menurun dan akan berhubungan dengan sistem renin angiotensin(Kusumastuty, 2016). Namun penelitian lainnya menemukan bahwa hubungan antara kalium dan tekanan darah terlihat hanya di posisi berdiri pada saat pengukuran. Hal ini dikarenakan postur yang berubah dari posisi terlentang ke posisi berdiri melibatkan aktivasi pada sistem saraf simpatik, yang diketahui menyebabkan perubahan pada fungsi kalium didalam ekstra dan instraseluler (Tulungnen, Sapulete, \& Pangemanan, 2016).

\section{Hubungan Persentase Lemak Tubuh dengan Kejadian Hipertensi Terkontrol dan Tidak Terkontrol pada Pralansia}

Berdasarkan hasil penelitian pada (Tabel 2) dengan menggunakan uji chi-square didapatkan hasil bahwa tidak ada hubungan yang signifikan antara persentase lemak tubuh dengan kejadian hipertensi terkontrol dan tidak terkontrol pada pralansia dengan nilai $p$-value 0.984 ( $p>0.05)$. Hal ini sejalan dengan penelitian (Sukmanah, 2017) dan (Luh, Trisna, \& Maryanto, 2019) yang menyatakan 
tidak adanya hubungan antara persen lemak tubuh dengan hipertensi. Hal ini tidak sejalan dengan hasil penelitian (Sari, 2018) yang menunjukkan terdapat hubungan yang bermakna antara kadar lemak tubuh total dengan tekanan darah terkendali pada pasien hipertensi primer dengan nilai $p$ value 0.003 .

Penelitian ini tidak menemukan adanya hubungan antara persentase lemak tubuh dengan kejadian hipertensi terkontrol dan tidak terkontrol, kemungkinan dikarenakan penumpukan lemak tersebut bukan di bagian visceral atau abdominal melainkan di bagian subkutan (Wirawanni, 2011). Hal ini dapat terlihat dari postur tubuh para responden di lapangan yang rata-rata responden memiliki bentuk tubuh seperti buah pir yang menandakan penumpukan lemak terjadi dibagian perut, pinggul, paha dan bokong. Seiring dengan penambahan usia, jumlah lemak tubuh total makin meningkat terutama simpanan lemak bagian visceral atau lemak pusat (Sarbini, Zulaekah, \& Isnaeni, 2019). Hilangnya massa otot juga akan memperlambat proses metabolisme sekaligus menurunkan ketersediaan energi untuk beraktivitas sehingga lemak didalam tubuh akan semakin meningkat. Metabolisme basal yang menurun sekitar 5-25\% akan mempengaruhi proses tubuh dalam memanfaatkan zat gizi yang masuk kedalam tubuh dan akan menyebabkan glukosa yang menempel pada lemak tubuh sulit diproses (Jafarinasabian, Inglis, Reilly, \& Kelly, 2017).

Obesitas sentral paling banyak terjadi karena adanya penumpukan lemak viseral pada daerah abdomen. Hipertensi dapat meningkat jika lemak viseral didalam tubuh tinggi yang berakibat terhadap penekanan pada organ yang terdapat di dalam rongga abdomen yaitu salah satunya adalah ginjal (Sari, 2018). Ginjal yang mengalami penekanan akan membuat reabsorbsi di tubulus renal meningkat kemudian mengganggu tekanan natriuresis dan membuat peningkatan volume di darah melalui aktivasi saraf simpatis serta sistem Renin-Angiotensin-Aldosteron (RAA). dalam retensi air dan natrium (Ulumuddin \& Yhuwono, 2018). Beberapa penelitian menunjukkan bahwa komposisi lemak mungkin mempengaruhi tingkat tekanan darah yang mengakibatkan tekanan darah tidak terkontrol. Berbagai mekanisme salah satunya melepaskan asam lemak bebas sistemik dapat meningkatkan resistensi insulin dan fungsi endotel. Selain itu Jaringan adiposa adalah substrat yang menghasilkan peningkatan kadar hormon leptin sehingga mengarahkan ke aktivasi saraf simpatis. Pada akhirnya, aktivitas yang berlebihan pada saraf simpatis yang diinduksi menyebabkan peningkatan tekanan darah (Meelab et al., 2019).

\section{Hubungan Kepatuhan Diet Rendah Garam dengan Kejadian Hipertensi Terkontrol dan Tidak Terkontrol pada Pralansia}

Berdasarkan hasil penelitian (tabel 2) dengan menggunakan uji chi-square didapatkan hasil bahwa ada hubungan yang signifikan antara kepatuhan diet rendah garam dengan kejadian hipertensi terkontrol dan tidak terkontrol pada pralansia dengan nilai $p$-value $0.000(\mathrm{p}<0.05)$. Hal ini juga sejalan dengan penelitian yang dilakukan oleh (Desriyesi, 2016) dan (Hermawati \& Sartika, 2014) menyatakan ada hubungan antara kepatuhan menjalankan diet rendah garam dengan kejadian hipertensi terkendali dan tidak terkendali.

Salah satu diet hipertensi untuk memepertahankan keadaan tekanan darah, yakni diet rendah garam. Tujuan diet rendah garam adalah membantu menghilangkan retensi garam atau air dalam jaringan tubuh dan menurunkan tekanan darah pada pasien hipertensi (Almatsier, 2010). Kebiasaan mengonsumsi garam yang berlebih di Indonesia dikarenakan budaya masak-memasak masyarakat yang umumnya boros menggunakan garam dan MSG (Douman, 2013). Hal ini didukung dengan hasil wawancara menggunakan kuesioner kepatuhan diet rendah garam, ketidakpatuhan disebabkan karena sebagian responden masih mengonsumsi atau tidak bisa mengurangi makanan yang diawetkan dan penggunaan bumbu dapur yang mengandung garam, monosodium glutamat (MSG), kecap asin dan terasi. Pada penelitian (Kamran, Shekarchi, Sharifian, \& Heydari, 2016) menyatakan responden yang memiliki hipertensi tidak terkontrol rata-rata mengonsumsi garam lebih tinggi dari yang dianjurkan, rata- rata asupan garam yang dikonsumsi sebesar 9,3 g/hari. Hal ini tidak sesuai dengan yang dianjurkan oleh World Health Organization yaitu hanya $5 \mathrm{~g} /$ hari. Berbeda dengan ratarata asupan garam yang dikonsumsi oleh responden dengan tekanan darah lebih stabil yakni sebesar 
$4.6 \mathrm{~g} /$ hari (Keyzer, Tilleman, Ampe, Henauw, \& Huybrechts, 2015). Ketidakpatuhan sering diakibatkan adanya sikap negatif yang sering muncul pada penderita hipertensi karena adanya kejenuhan atau tidak terbiasa menjalankan diet rendah garam (Agrina, Rini, \& Hairitama, 2011). Padahal sikap menjadi faktor yang paling kuat, karena dengan sikap ingin sembuh dan keinginan untuk menjaga kondisi tubuh tetap sehat akan berpengaruh terhadap penderita untuk mengontrol diri dalam berperilaku sehat (Mapagerang \& Alimin, 2018).

Faktor lainnya yang dapat menyebabkan seseorang tidak patuh menjalankan diet rendah garam yaitu usia responden. Responden dengan umur 45-59 tahun atau masa pralansia memiliki tingkat kematangan yang dapat berpengaruh pada kemampuan untuk berperilaku baik atau buruk dalam melakukan kebiasaan-kebiasaan yang melibatkan dirinya, sehigga untuk menerima informasi yang diberikan akan lebih sulit (Susanti, 2019). Hal ini bisa disebabkan karena penderita hipertensi dengan usia tersebut ingin diikuti semua keinginannya, baik dalam segi makanan karena ada anggapan dari masyarakat bahwa semakin bertambahnya usia seseorang pola pikirannya semakin kekanakan yang selalu ingin diikuti keinginannya, sehingga diet yang dianjurkan tidak berjalan dengan baik. Penderita hipertensi yang dapat melakukan (Keyzer et al., 2015) pengurangan asupan natrium selama 4 minggu dapat mengurangi tekanan darah pada pasien hipertensi tidak terkontrol. Pembatasan garam dapat meningkatkan aktivitas simpatis dan resistensi insulin. pembatasan asupan garam dikaitkan dengan atenuasi persisten dari respons aktivitas simpatis otot terhadap stimulasi dan deaktivasi baroreseptor. Selain itu ada hubungan antara pengurangan sensitivitas baro reseptor dan peningkatan aktivitas saraf simpatis otot secara bersamaan, yaitu berkurangnya kemampuan refleks untuk mendapatkan pengaturan nada simpatik yang tepat menyebabkan efek simpatostimulasi dari asupan natrium yang sangat rendah. Resisten insulin merupakan hasil dari aktivasi simpatis atau mungkin dari peningkatan kadar insulin itu sendiri memiliki pengaruh sympathoexcitatory. Suplai garam yang rendah juga dapat menyebabkan aktivasi sistem simpatis melalui pembongkaran reseptor kardiopulmoner (Grillo, Salvi, Coruzzi, Salvi, \& Parati, 2019).

\section{SIMPULAN}

Berdasarkan hasil penelitian yang telah dilakukan, dapat disimpulkan ada hubungan dan kepatuhan diet rendah garam dengan kejadian hipertensi terkontrol dan tidak terkontrol pada pralansia. Sedangkan, asupan kalium dan persen lemak tubuh tidak menunjukkan adanya hubungan dengan kejadian hipertensi terkontrol dan tidak terkontrol pada pralansia di RW 03 Lubang Buaya dan RW 09 Kampung Tengah, Jakarta tahun 2020

\section{SARAN}

Berdasarkan penelitian ini diharapkan kepada responden yang telah menderita hipertensi untuk merubah gaya hidupnya dengan rutin mengonsumsi makanan yang tinggi kalium seperti buah dan sayuran, mengurangi makanan yang mengandung garam minimal $1 \mathrm{sdt}$ perhari, dan kesadaran untuk rutin minum obat antihipertesi serta selalu memeriksakan tekanan darah secara teratur atau mengontrol tekanan darah. serta diharapkan agar peneliti selanjutnya menggunakan desain penelitian yang berbeda yaitu case control ataupun kohort

\section{DAFTAR PUSTAKA}

Afifah, E. (2016). Asupan Kalium-Natrium Dan Status Obesitas Sebagai Faktor Risiko Kejadian

Hipertensi Pasien Rawat Jalan Di Rs Panembahan Senopati Bantul Yogyakarta. Jurnal Gizi Dan

Dietetik Indonesia, 4(1), 41-48.

Agrina, Rini, S. S., \& Hairitama, R. (2011). Kepatuhan Lansia Penderita Hipertensi Dalam Pemenuhan

Diet Hipertensi. Program Studi Ilmu Keperawatan Universitas Riau, 6 (1), 46-53.

Almatsier, S. (2010). Penuntun Diet Edisi Baru. Jakarta: Pt. Gramedia Pustaka Utama.

Anwar, R. (2014). Konsumsi Buah Dan Sayur Serta Konsumsi Susu Sebagai Faktor Risiko Terjadinya

Hipertensi Di Puskesmas S . Parman Kota Banjarmasin. Jurnal Skala Kesehatan, 5(1).

Desriyani, R., Wahyudi, J. T., \& Suratun. (2019). Pengaruh Senam Hipertensi Terhadap Kualitas Tidur 
Pasien Dengan Hipertensi Di Rumah Sakit Muhammadiyah Palembang. Indonesian Journal For Health Sciences, 3(2), 88-95.

Desriyesi, D. (2016). Hubungan Kepatuhan Tentang Diet, Pengobatan Dan Aktivitas Fisik Terhadap Pengendalian Tekanan Darah Pada Lansia Penderita Hipertensi Di Wilayah Kerja Puskesmas Belimbing Padang. Universitas Andalas.

Dinkes Dki Jakarta. (2018). Dinas Kesehatan Dki Jakarta.

Douman. (2013). Waspadai Stroke Usia Muda. Jakarta: Cerdas Sehat.

Fitri, Y., Rusmikawati, Zulfah, S., \& Nurbaiti. (2018). Hipertensi Pada Usia Lanjut ( Sodium And

Potassium Intake As A Factor Causing Hypertension In The Elderly ). Aceh Nutrition Journal, 3(2), 158-163. Https:/ / Doi.Org/10.30867/ Action.V3i2.117

Grillo, A., Salvi, L., Coruzzi, P., Salvi, P., \& Parati, G. (2019). Sodium Intake And Hypertension. Nutrients 2019, 11, 1-16. Https:/ / Doi.Org/10.3390/Nu11091970

Hermawati, \& Sartika, W. (2014). Berdasarkan Pola Diet Dan Kebiasaan Olah Raga. Jurnal Kesehatan Masyarakat, 8(1), 8-14.

Jafarinasabian, P., Inglis, J. E., Reilly, W., \& Kelly, O. J. (2017). Aging Human Body : Changes In Bone , Muscle And Body Fat With Consequent Changes In Nutrient Intake. Journal Of Endocrinolog, 234, 37-51. Https://Doi.Org/10.1530/Joe-16-0603

Kamran, A., Azadbakht, L., Sharifirad, G., Mahaki, B., \& Sharghi, A. (2014). Sodium Intake , Dietary Knowledge, And Illness Perceptions Of Controlled And Uncontrolled Rural Hypertensive Patients. International Journal Of Hypertension, 2014, 1-7. Https:/ / Doi.Org/Http:/ / Dx.Doi.Org/10.1155/2014/245480

Kamran, A., Shekarchi, A. A., Sharifian, E., \& Heydari, H. (2016). The Comparison Of Dietary Behaviors Among Rural Controlled And Uncontrolled Hypertensive Patients. Advances In Preventive Medicine, 2016, 7.

Keyzer, W. De, Tilleman, K., Ampe, J., Henauw, S. De, \& Huybrechts, I. (2015). Effect Of Sodium Restriction On Blood Pressure Of Unstable Or Uncontrolled Hypertensive Patients In Primary Care. 9(2), 180-185. Https:/ / Doi.Org/10.4162/Nrp.2015.9.2.180

Kurniasih, D., Pangestuti, D. R., \& Aruben, R. (2017). Hubungan Konsumsi Natrium, Magnesium, Kalium, Kafein, Kebiasaan Merokok Dan Aktivitas Fisik Dengan Hipertensi Pada Lansia (Studi Di Desa Wilayah Kerja Puskesmas Duren Kabupaten Semarang Tahun 2017) Dewi. Jurnal Kesehatan Masyarakat, 5(4), 629-639.

Kusumastuty, D. (2016). Indonesian Journal Of Human Nutrition. 3(1), 19-28.

Liman, L. M. S., Arif, H., \& Surjadi, C. (2015). Prevalensi Dan Determinan Penyakit Tidak Menular Pada Pralansia Dan Lansia Ekonomi Menengah Di Tangerang. Damianus Journal Of Medicine, 14(3), 161-171.

Litbangkes Ri. (2018). Riset Kesehatan Dasar.

Luh, N., Trisna, G., \& Maryanto, S. (2019). The Correlation Between Percentage Of Body Fat And Waist Circumference With Hypertension On Students In Hidayah Vocational School Semarang. Jurnal Gizi Dan Kesehatan, 11(25), 46-53.

Ma, T. S. H., Bchir, M. B., Gindan, Y. Y. Al, Govan, L., Hankey, C. R., Lean, M. E. J., \& Bchir, M. B. (2019). Associations Of Body Fat And Skeletal Muscle With Hypertension. J Clin Hyperten, 21(September 2018), 230-238. Https:/ / Doi.Org/10.1111/Jch.13456

Mapagerang, R., \& Alimin, M. (2018). Hipertensi Dengan Kontrol Diet Rendah Garam. 7.

Meelab, S., Lertthanaporn, S., Suwanthip, K., Songsaengthum, C., Naowanit, N., Rangsin, R., \& Id, B. S. (2019). Prevalence And Associated Factors Of Uncontrolled Blood Pressure Among 
Hypertensive Patients In The Rural Communities In The Central Areas In Thailand : A CrossSectional Study. Plos One, 14. Https://Doi.Org/Https:/ Doi.Org/10.1371/Journal.Pone.0212572

Purwandari, K. P. (2017). Hubungan Pengetahuan Diet Dan Komplikasi Hipertensi Terhadap Tingkat Kepatuhan Diet Hipertensi Masyarakat Di Kelurahan Nambangan Selogiri Wonogiri Kristiana Puji Purwandari. Keperawatan Gsh.

Putri \& Kartini. (2014). Hubungan Asupan Kalium, Kalsium Dan Magnesium Dengan Kejadian Hipertensi Pada Wanita Menopause Di Kelurahan Bojongsalaman, Semarang. Journal Of Nutrition College, 3(4), 580-586.

Saint-Remy, A., Somja, M., Gellner, K., Weekers, L., \& Bonvoisin, C. (2012). Urinary And Dietary Sodium And Potassium Associated With Blood Pressure Control In Treated Hypertensive Kidney Transplant Recipients: An Observational Study. Bmc Nephrology, 13(121), 1-10.

Sarbini, D., Zulaekah, S., \& Isnaeni, F. N. (2019). Gizi Geriatri (Pertama). Jawa Tengah: Muhammadiyah University Press.

Sari, E. A. (2018). Hubungan Kadar Lemak Tubuh Total Dan Lemak Viseral Dengan Tekanan Darah Terkendali Pada Pasien Hipertensi Primer Di Puskesmas Beji, Depok Periode Desember 2017 - Januari 2018. Universitas Pembangunan Nasional Veteran Jakarta.

Sukmanah, R. (2017). Hubungan Antara Presentase Lemak Tubuh Dan Kejadian Hipertensi Di Puskesmas Bojongsoang Kabupaten Bandung. Politeknik Kesehatan Kemenkes Bandung.

Susanti. (2019). Kepatuhan Diet Dengan Kejadian Komplikasi Pada Penderita. Adi Husada Nursing Journal, 5(1), 30-36.

Tulungnen, R. S., Sapulete, I. M., \& Pangemanan, D. H. (2016). Hubungan Kadar Kalium Dengan Tekanan Darah Pada Remaja Di Kecamatan Bolangitang Barat Kabupaten Bolaang Mongondow Utara. Jurnal Kedokteran Klinik (Jkk), 1(2), 37-45.

Ulumuddin, I., \& Yhuwono, Y. (2018). Hubungan Indeks Massa Tubuh Dengan Tekanan Darah Pada Lansia Di Desa Pesucen, Banyuwangi. Jurnal Kesehatan Masyarakat, 13(1), 1-6.

Wirawanni, S. \&. (2011). Faktor - Faktor Yang Berhubungan Dengan Tekanan Darah Pada Pegawai Negeri Sipil Sma N 8 Semarang. Jurnal Visikes, 10(2), 114-122.

World Health Organization. (2013). A Global Brief On Hyper - Tension World Health Day 2013.

Yuliana, Aniestia, Handayani, \& Fitria. (2014). Kepatuhan Diet Rendah Garam Pada Pasien Hipertensi Dipuskesmas Srondol, Semarang. Universitas Diponegoro. 